\title{
Comparison of helminth and hard tick infestation between riding and work horses in Ahwaz, Iran
}

\author{
Mohammad Khosravi • Fariba Kavosh • Ahmad Taghavi-Moghadam • \\ Shamsodin Ghaem-Maghami • Khodadad Pirali-Kheirabadi • Peyman Rahimi-Feyli • \\ Shahrokh Navid-Pour • Arash Amin-Pour • Fateme Arbabi
}

Received: 24 November 2010 / Accepted: 7 July 2011 / Published online: 21 July 2011

(C) The Author(s) 2011. This article is published with open access at Springerlink.com

\section{Introduction}

Millions of dollars are spent every year for internal and external parasite control in horses; however, parasites remain one of the most important problems affecting their health and well-being (Raynaud et al. 1983).

All horses have internal parasites and, if left untreated, ticks and worms can rob a horse of precious blood nutrients

M. Khosravi $(\bowtie)$

Department of Microbiology, Faculty of Veterinary Medicine, University of Tehran,

Tehran- Azadi Avenue- Qareeb Street,

1419963111, Tehran, Iran

e-mail: khosravi.m@ut.ac.ir

F. Kavosh · A. Taghavi-Moghadam · S. Ghaem-Maghami Razi Vaccine and Serum Research Institute-Ahwaz Branch, Ahwaz, Iran

K. Pirali-Kheirabadi

Department of Pathobiology, Faculty of Veterinary Medicine, Shahrekord University,

Shahrekord, Iran

P. Rahimi-Feyli

Department of Clinical Sciences, Faculty of Veterinary Medicine, University of Tehran,

Tehran, Iran

S. Navid-Pour

Razi Vaccine and Serum Research Institute-Karaj Branch,

Karaj, Iran

\author{
A. Amin-Pour \\ Department of Pathobiology, Faculty of Veterinary Medicine, \\ University of Tehran, \\ Tehran, Iran \\ F. Arbabi \\ Faculty of Veterinary Medicine, Shahrekord University, \\ Shahrekord, Iran
}

and energy. Problems associated with parasite infection include diarrhoea, colic, weight loss, poor growth, emaciation, impaired growth, predisposition to other infectious diseases and unexpected sudden death (Taylor et al. 2007).

The common parasitic infestations of horses are caused by mange mites, lice, bots, ticks, roundworms, palisade worms, Trichonema and pinworms (Kingscote 1938). Ticks have eight legs (insects have six); non-engorged, they are small, flat and brown. Adult engorged ticks are dark blue-grey and the size of a pea. When they drop off, they leave behind a craterlike sore in the middle of an itchy/painful lump (George et al. 2002). Ticks are external parasites which suck blood from the host animal. Two general groups of ticks attack horses: hard ticks and soft ticks. Hard ticks have a long association with the host, feed slowly, take a large blood meal, drop from the host to moult and lay many eggs (Kaufman et al. 2009).

The treatment of infected animals depends on the results of diagnostic tests, counts of eggs per gram of faeces (EPG) as well as methods for culturing, counting and identifying third-stage (L3) strongyle larvae per gram of faeces (LPG). For horses, such information does not exist in the published literature (Nielsen et al. 2010). A faecal egg count test is a microscopic examination for parasite eggs in fresh manure. This simple test can indicate which parasites are present and in what numbers. Adult parasites lay eggs or proglottids (portions of their bodies containing eggs) that pass out of the intestinal tract in the faeces. Internal parasite eggs can be detected in the faeces by performing a faecal egg count test. A faecal egg count test establishes the number of parasite eggs present in each gram of manure tested (EPG). Traditionally, a horse with an EPG value of 200 to 500 would be considered a candidate for treatment. In a herd, an average EPG value between all horses of 100 to 300 has long been considered the threshold between normal and unusual levels of parasite infestation (Evans and Rood 2009). 
Table 1 Sex-related prevalence of helminthic infection in work and riding horse

\begin{tabular}{|c|c|c|c|c|c|c|c|c|}
\hline \multirow[t]{3}{*}{ Helminth } & \multicolumn{6}{|l|}{ Horse type } & \multicolumn{2}{|c|}{ Total number of horses } \\
\hline & \multicolumn{3}{|c|}{ Work horse } & \multicolumn{3}{|c|}{ Riding horse } & \multirow[b]{2}{*}{ Male (\%) } & \multirow[b]{2}{*}{ Female $(\%)$} \\
\hline & Male $(\%)$ & Female $(\%)$ & Total $(\%)$ & Male $(\%)$ & Female $(\%)$ & Total (\%) & & \\
\hline Small Strongylus & $5(22.7)$ & $12(42.8)$ & $17(34) \mathrm{a}$ & - & - & $\mathrm{b}^{-}$ & $5(9.8)$ & $12(17.4)$ \\
\hline Dicrocoelium & $11(50)$ & $17(60.7)$ & $28(56) \mathrm{c}$ & $4(13.8)$ & $8(19.5)$ & $12(17.1) \mathrm{d}$ & $15(29.4)$ & $25(36.2)$ \\
\hline Oxiuris & $5(22.7)$ & $8(28.5)$ & $13(26)$ & $5(17.2)$ & $4(9.7)$ & $9(12.9)$ & $10(19.6)$ & $12(17.4)$ \\
\hline Parascaris & $13(59.1)$ & $9(32.1)$ & $22(44) \mathrm{e}$ & $4(13.8)$ & $3(7.3)$ & $7(10) \mathrm{f}$ & $17(33.3)$ & $12(17.4)$ \\
\hline
\end{tabular}

Within rows, values followed by different letters are significantly different $(P<0.05)$

Faecal worm egg counts, if conducted correctly, can also determine the general type of parasites present such as pinworms, threadworms, roundworms (Parascaris), strongyles and tapeworms. The Modified Wisconsin Sugar Flotation Method is highly sensitive for use with horses (three eggs per $1 \mathrm{~g}$ of sample) such that negative counts indicate the absence of adult parasites. Repeated negative information on the total number of worm eggs shed per pound of faeces can determine the rate by which an animal is re-contaminating its environment (Coates 2007). In the Ahwaz region, worm parasite infection is one of the most abundant animal diseases which cause economic losses and health problems for the infected animal husbandries. The aim of this study was to determine the prevalence of external and internal parasite infestation in about 120 horses in this region since little data exist in this field in Iran.

\section{Materials and methods}

In this study, 120 horses (70 riding and 50 work horses) were chosen from Ahwaz and its suburbs for parasitic inspection. The samples were transferred to the Razi Institute in an ice box; those samples which took longer to transfer were diluted $1: 3$ with $10 \%$ formalin. Floatation of samples with saturated $\mathrm{NaCl}$ or $\mathrm{MgSO}_{4}$ was carried out for nematode and cestode eggs and precipitation for trematode eggs. Finally, the eggs were observed under a microscope with Mach Master 2 chamber slide and the number of parasite eggs per gram of stool was reported. The detected strongyle eggs were cultured at $27^{\circ} \mathrm{C}$ for 7 days for development of third-stage larvae. Baermann apparatus was used to isolate these larvae from the cultures. The total length, number of intestinal cells and number of intestinal cell rows were calculated. For tick contamination, location and complete specification of horses were registered and total number of ticks separated were counted and transferred to the Razi Institute. The samples were examined using a dissecting microscope to determine the parasite type and photographs were taken of positive samples.

For the detection of worm contamination, $3 \mathrm{~g}$ of faecal sample was mixed with a saturated sugar solution designed to float the eggs out of the faecal matter. The samples were strained to remove large debris and the strained samples were poured into a $15-\mathrm{ml}$ taper test tube and centrifuged at a low RPM $(<1,000)$ for $5 \mathrm{~min}$, which increases the egg recovery rate by a significant amount. After centrifugation, a few drops of sugar were added to form a meniscus on top of the tube. A cover slip was placed on the top of the tube for 2 min, removed and examined under the microscope at $\times 40$ magnification. Eggs were identified to type and counted. The collection process was conducted using a sealable bag or baggie; the bag was inverted like a glove and freshly dropped faecal material the size of a golf ball from each horse was picked up to check for parasites.
Table 2 Age-related prevalence of helminthic infection in work and riding horse

\begin{tabular}{|c|c|c|c|c|c|c|}
\hline \multirow[t]{3}{*}{ Helminth } & \multicolumn{4}{|l|}{ Horse type } & \multicolumn{2}{|c|}{ Total number of horses } \\
\hline & \multicolumn{2}{|c|}{ Work horse } & \multicolumn{2}{|c|}{ Riding horse } & & \\
\hline & $\leq 5(\%)$ & $>5(\%)$ & $\leq 5(\%)$ & $>5(\%)$ & $\leq 5(\%)$ & $>5(\%)$ \\
\hline Small Strongylus & $8(44.4)$ & $9(28.1)$ & - & - & $8(17.7)$ & $9(12)$ \\
\hline Dicrocoelium & $12(66.6)$ & $16(50)$ & $7(26)$ & $5(11.6)$ & $19(42.2)$ & $21(28)$ \\
\hline Oxiuris & $6(33.3)$ & $7(21.8)$ & $5(18.5)$ & $4(9.3)$ & $11(24.4)$ & $11(14.6)$ \\
\hline Parascaris & $14(77.7)$ & $8(25)$ & $5(18.5)$ & $2(4.6)$ & $19(42.2)$ & $10(13.3)$ \\
\hline
\end{tabular}


Table 3 Sex-related prevalence of tick infection in work and riding horse

\begin{tabular}{|c|c|c|c|c|c|c|c|c|}
\hline \multirow[t]{3}{*}{ Tick } & \multicolumn{6}{|c|}{ Horse type } & \multirow{2}{*}{\multicolumn{2}{|c|}{ Total number of horses }} \\
\hline & \multicolumn{3}{|c|}{ Work horse } & \multicolumn{3}{|c|}{ Riding horse } & & \\
\hline & Male $(\%)$ & Female $(\%)$ & Total $(\%)$ & Male $(\%)$ & Female $(\%)$ & Total $(\%)$ & Male $(\%)$ & Female $(\%)$ \\
\hline Hyalomma & $12(54.5)$ & $16(57.1)$ & $28(56) \mathrm{a}$ & $8(27.5)$ & $9(21.9)$ & $17(24.2) b$ & $20(39.2)$ & $25(36.2)$ \\
\hline Rhipicephalus & $4(18.2)$ & $7(25)$ & $11(22)$ & $3(10.3)$ & $2(4.8)$ & $5(7.1)$ & 7 (13.7) & $9(13)$ \\
\hline Boophilus & - & $2(7.1)$ & $2(4)$ & - & - & - & - & $2(2.8)$ \\
\hline
\end{tabular}

Within rows, values followed by different letters are significantly different $(P<0.05)$

The statistical analysis was carried out using SPSS 16. Chi-square was performed to compare the difference between infestation of work horses and riding horses, between sex and infection rate and between age of the horses and infection rate. Differences were considered significant at $P<0.05$.

\section{Results}

Total infection was 55 (45.83\%) and among infected horses internal parasite infestation was $17(24.28 \%)$ and 38 $(75.72 \%)$ in riding horses and work horses, respectively.

The result of the egg culture showed that all of the L3 larvae were determined as small strongyles. In work horses, 28 (56\%), 17 (34\%), 13 (26\%) and 22 (44\%) were infected with Dicrocoelium, Strongylus, Oxiuris and Parascaris, respectively. In riding horse, 12 (17.14\%), 9 (12.85\%) and $7(10 \%)$ were infected with Dicrocoelium, Oxiuris and Parascaris, respectively (Tables 1 and 2).

From a total of 120 horses (70 riding and 50 work horses), tick contamination was seen in 63 horses (52\%). The total number of separated ticks was $803(690$ Hyalomma, 97 Rhipicephalus and 16 Boophilus) with an average of 13 ticks per horse. The results of tick contamination are shown in Tables 3 and 4. Statistical analysis indicated that there were significant differences between infection in the work horses and riding horses with

Table 4 Age-related prevalence of tick infection in work and riding horse

\begin{tabular}{|c|c|c|c|c|c|c|}
\hline \multirow[t]{3}{*}{ Tick } & \multicolumn{4}{|c|}{ Horse type } & \multirow{2}{*}{\multicolumn{2}{|c|}{$\begin{array}{l}\text { Total number of } \\
\text { horses }\end{array}$}} \\
\hline & \multicolumn{2}{|c|}{ Work horse } & \multicolumn{2}{|c|}{ Riding horse } & & \\
\hline & $\leq 5(\%)$ & $>5(\%)$ & $\leq 5(\%)$ & $>5(\%)$ & $\leq 5(\%)$ & $>5(\%)$ \\
\hline Hyalomma & $9(50)$ & $19(59.3)$ & $5(18.5)$ & $12(28)$ & $14(31.1)$ & $31(41.3)$ \\
\hline Rhipicephalus & $5(27.7)$ & $6(18.7)$ & $1(3.7)$ & $4(9.3)$ & $6(13.3)$ & $10(13.3)$ \\
\hline Boophilus & $1(5)$ & $1(3.1)$ & - & - & $1(2.2)$ & $1(1.3)$ \\
\hline
\end{tabular}

small strongyles, Dicrocoelium dendriticum, Parascaris equorum, Hyalomma and Boophilus $(P<0.05)$, but there were no significant differences between infection of the work horses and riding horses with Oxyuris and Rhipicephalus. Additionally, no significant differences were seen between age and infection rate and between sex and infection rate. The result of the EPG (egg per gram) count showed 38 (14 riding horses and 24 work horses) samples which had $\geq 200$ EPG and 12 (three riding horses and nine work horses) $>200 \mathrm{EPG}$ (Fig. 1).

\section{Discussion}

The objective of this study was to determine and compare the prevalence of equine helminths and external parasites in work and riding horses in Ahwaz and its suburb in Iran. Statistical analysis indicated that there were significant differences in infection between work horses and riding horses and this may be due to the lack of veterinary care relating to parasitic infection by the horse owners who are generally on a low income. Due to their prohibitive costs, the use of anthelmintics is limited. Consequently, owners do not use them regularly and there is no parasite control programme in this region. In general, in Iran, as in many other parts of the world, the veterinary attention given by work horse owners to their animals is below the level that it

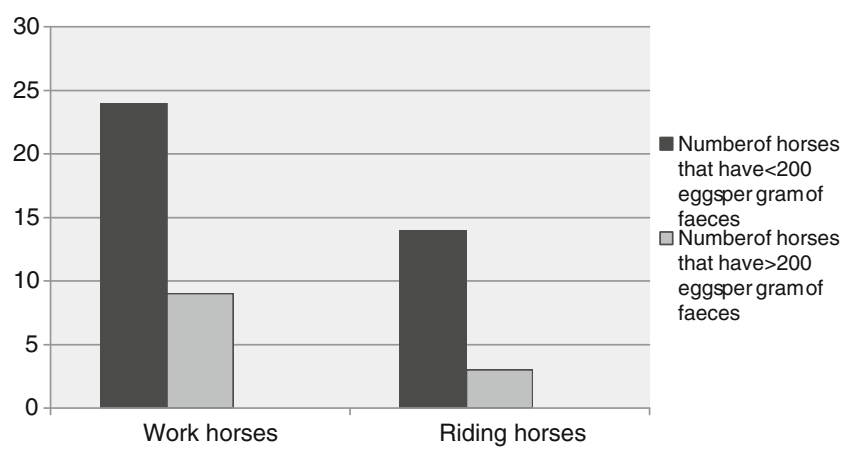

Fig. 1 Horse classification based on parasite eggs in their faeces 
should be. This might be partly due to the incorrect perception that working horses do not require a lot of care.

In this study, no significant differences were seen between age and infection rate and between sex and infection rate; our results are in agreement with some previous studies (Boxell et al. 2004; Francisco et al. 2009; Saeed et al. 2010). Different study results from various part of the world have reported diverse prevalences in parasitic infection in horses (Eslami et al. 2005; Papazahariadou et al. 2009; Saeed et al. 2010). In an earlier study on gastrointestinal parasite infection from 221 work horses, $72.96 \%, 22.6 \%$ and $12.2 \%$ were infected with Strongylus, Oxiuris and Parascaris, respectively (Tavakoli 1997). With some differences from our results, Saeed et al. (2010) indicated that $65.51 \%$ of the samples were positive for helminthes eggs and contamination with Parascaris and Dicrocelium were $5 \%$ and $2.5 \%$, respectively. In another study in 2009, 29 stud and mare farms were selected in Brazil. The contamination rate was $94.6 \%, 14.1 \%$ and $7.9 \%$ for Strongylus, Oxiuris and Parascaris in mares, respectively. For stud contamination, the rate was $96.4 \%, 50 \%$ and $57.1 \%$ with Strongylus, Oxiuris and Parascaris (Martins et al. 2009). One author in Greece, based on 300 faecal samples from race and traction horses, yielded $62.4 \%$ positive results, $45.6 \%$ for small strongyles, $1.7 \%$ for Parascaris equorum and $4.1 \%$ for Oxyuris equi (Sotiraki et al. 1997). Labruna et al. found Boophilus with a prevalence rate of $10 \%$ on horses in the state of São Paulo, Brazil (Labruna et al. 2001).

Animals need periodic deworming. A comprehensive parasite control programme should include pasture management, environmental sanitation and regular anthelmintic administration. Performing routine faecal egg counts will help to determine the efficacy of treatment and control programmes. Anthelmintics should be chosen conscientiously and their use should be rotated slowly to decrease the occurrence of resistance.

Acknowledgment This work has been supported by the vaccine and serum research of Razi Institute-Ahwaz branch. We thank Hamid Bahrani for the assistance in sample collection.

Open Access This article is distributed under the terms of the Creative Commons Attribution Noncommercial License which permits any noncommercial use, distribution, and reproduction in any medium, provided the original author(s) and source are credited.

\section{References}

Boxell AC, Gibson KT, Hobbs RP, Thompson RC (2004) Occurrence of gastrointestinal parasites in horses in metropolitan Perth, Western Australia. Aust Vet J 82:91-95

Coates B (2007) SWAT! Equine external parasite control: management. SA Horseman 2:38-40

Eslami A, Bokai S, Tabatabai V (2005) Equine parasites in Iran. J Equine Vet Sci 25:143-144

Evans PA, Rood K (2009) Faecal egg count tests improve deworming programs. http://extension.usu.edu/files/publications/publication/ AG_Equine_2009-01pr.pdf

Francisco I, Arias M, Cortinas FJ, Francisco R, Mochales E, Dacal V, Suarez JL, Uriarte J, Morrondo P, Sanchez-Andrade R, Diez-Banos P, Paz-Silva A (2009) Intrinsic factors influencing the infection by helminth parasites in horses under an oceanic climate area (NW Spain). J Parasitol Res. doi:10.1155/2009/616173

George JE, Davey RB, Pound JM (2002) Introduced ticks and tickborne diseases: the threat and approaches to eradication. Vet Clin North Am Food Anim Pract 18:401-416

Kaufman PE, Koehler PO, Butle JF (2009) External parasites on horses. http://edis.ifas.ufl.edu/ig139

Kingscote AA (1938) Common parasites of Canadian animals. Can J Comp Med 2:47-55

Labruna MB, Kerber CE, Ferreira F, Faccini JLH, De Waal DT, Gennari SM (2001) Risk factors to tick infestations and their occurrence on horses in the state of Sao Paulo, Brazil. Vet Parasitol 97:1-14

Martins IVF, Verocai GG, Correia TR, Melo RMPS, Pereira MJS (2009) Survey on control and management practices of equine helminthes infection. Pesquisa Vet Brasil 29:253-257

Nielsen MK, Baptiste KE, Tolliver SC, Collins SS, Lyons ET (2010) Analysis of multiyear studies in horses in Kentucky to ascertain whether counts of eggs and larvae per gram of faeces are reliable indicators of numbers of strongyles and ascarids present. Vet Parasitol 174:77-84

Papazahariadou M, Papadopoulos E, Diakou A, Ptochos S (2009) Gastrointestinal parasites of stabled and grazing horses in Central and Northern Greece. J Equine Vet Sci 29:233-236

Raynaud JP, Jones RM, Bliss DH, Le Stang JP, Kerboeuf D (1983) The control of parasitic gastroenteritis of grazing cattle in Normandy, France using the morantel sustained release bolus. Vet Parasitol $12: 261-272$

Saeed K, Qadir Z, Ashraf K, Ahmad N (2010) Role of intrinsic and extrinsic epidemiological factors on strongylosis in horses. J Anim Plant Sci 20:277-280

Sotiraki ST, Badouvas AG, Himonas CA (1997) A survey on the prevalence of internal parasites of equines in Macedonia and Thessalia-Greece. J Equine Vet Sci 17:550-552

Tavakoli M (1997) Survey on geographical distribution of ticks in Lorestan province. Tarbiat Modarres, Western Iran, p 112

Taylor MA, Coop RL, Wall RL (2007) Veterinary parasitology. Blackwell, London 